\title{
Effect of interfacial treatment on the thermal properties of thermal conductive plastics
}

\author{
L. M. Zhang, G. C. Dai \\ Shanghai 200237, P.R. China \\ Received 31 May 2007; accepted in revised form 14 July 2007
}

State Key Laboratory of Chemical Engineering, East China University of Science and Technology, 130 Meilong Road,

\begin{abstract}
In this paper, $\mathrm{ZnO}$, which is processed by different surface treatment approaches, is blended together with polypropylene to produce thermal conductive polymer composites. The composites are analyzed by Fourier transform infrared (FTIR) spectroscopy and scanning electron microscopy (SEM) to investigate the surface modification of filler, their distribution in the matrix and the condition of two-phase interface. Optimized content of filler surface modifier is investigated as well. The results showed that using low-molecular coupling agent produces positive effect to improve the interface adhesion between filler and matrix, and the thermal conductivity of the composite as well. Macro-molecular coupling agent can strongly improve two-phase interface, but it is not beneficial at obtaining a high thermal conductivity. The blend of $\mathrm{ZnO}$ without modification and polypropylene has many defects in the two-phase interface, and the thermal conductivity of the composite is between those of composites produced by previous two approaches. The surface treatment of the filler also allowed producing the composites with lower coefficient of thermal expansion (CTE). As for the content of low-molecular coupling agent, it obtains the best effect at $1.5 \mathrm{wt} \%$.
\end{abstract}

Keywords: polymer composites, thermal conductivity, coefficient of thermal expansion, interfacial treatment, coupling agent

\section{Introduction}

Thermal conductive polymer composites are normally produced by two approaches: one is to synthesize the polymers [1-2] with enhanced thermal conductivity, the other is to prepare the filled thermal conductive polymer composites [3-5]. In consideration of the difficulty of synthetic techniques, costs and many other factors, the second approach is usually adopted at present. To improve the thermal conductivity of thermal conductive polymer composites, following three approaches are very popular: firstly, it is to develop new type of thermal conductive filler, such as preparing micro-filler [6], highly oriented filler [7], 3D structure carbon fiber [8]; Secondly, it is through the surface modification of filler [9]; Thirdly, it is through the selection and optimization of the conditions of molding and processing.

At present, researches on the structure and performance of the interface of thermal conductive composites are mainly focused on their relationship with the mechanical performance of composite [10, 11], while there are very few reports about whether the two-phase interface conditions may influence the thermal conductivity of composite materials. If the relationship between the two-phase interface and thermal conductivity of materials could be nailed down, it would provide a relevant orientation for the future development of more advanced thermal conductive polymer composite.

This paper stressed the influence of filler particle surface modification on the thermal conductivity of 
composite. Several different types of coupling agents were tried to process the surface of filler, and the relationship between the category of coupling agent and the thermal conductivity of materials was investigated. The related principle was studied and the content of coupling agent was optimized as well.

\section{Experiment}

\subsection{Materials}

$\mathrm{ZnO}$ was obtained from Sinopharm Chemical Reagent Co., Ltd. (China) used for thermally conductive fillers. The matrix is a polypropylene (Y1600) supplied by SINOPEC Shanghai Petrochemical Co., Ltd. (China) (Table 1). The solvent such as iso-propylalcohol and xylene are supplied by Shanghai Dafei Industry \& Trade Co., Ltd. Heqiao Branch (China).

\subsection{Surface modification}

Two different methods were investigated to improve the properties of the interphase.

The first is aluminium and titanium complex coupling agent (OL-AT1618, $\mathrm{Al}(\mathrm{OR})_{\mathrm{n}}(\mathrm{OOCR})_{3-\mathrm{n}}$ Ti(OR') $)_{m}\left(\right.$ OOCR" $_{4-m}$, Fine Chemicals Department of Shanxi Provincial Institute of Chemical Industry, China, $5 \mathrm{~g}$ ) was diluted by $50 \mathrm{ml}$ isopropylalcohol, and then it was added to the weighed filler. Subsequently, the filler were processed by high speed stirring at $90^{\circ} \mathrm{C}$ for 120 minutes. After dried at $120^{\circ} \mathrm{C}$ for 24 hours, the surface modified fillers with small-molecular coupling agent were obtained.

The second is fillers were modified by the titanate coupling agent (NDZ-132, $\left(\mathrm{CH}_{3}\right)_{2} \mathrm{CHOTi}(\mathrm{OOCR})_{3}$, Nanjing Shuguang Chemical Group Co., Ltd., China) with the same method as mentioned above.

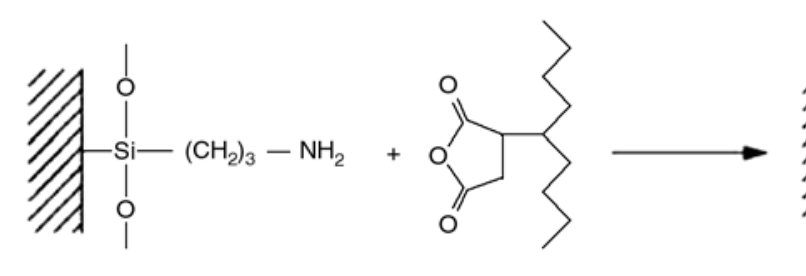

Figure 1. The reaction of the silane coupling agent with maleic anhydride grafted PP wax

Table 1. The property of $\mathrm{ZnO}$ and polypropylene

\begin{tabular}{|l|c|c|c|c|}
\hline & Density $\left[\mathbf{g} / \mathbf{c m}^{\mathbf{3}}\right]$ & Thermal conductivity $[\mathbf{W} / \mathbf{m} \cdot \mathbf{K}]$ & Size [nm] & Shape \\
\hline $\mathrm{ZnO}$ & 5.6 & 29 & $200 \pm 100$ & grainy \\
\hline Polypropylene & 0.905 & 0.26 & - & - \\
\hline
\end{tabular}


filler can be observed by FTIR (Magna-IR 550, THERMO NICOLET, USA).

SEM (JSM-6360LV, JEOL, Japan) was used to observe the surface graft layer of the filler and the distribution of the filler in the matrix.

CTE measurements were performed on a thermal expansion instrument (DIL $402 \mathrm{PC}$, NETZSCH, GER). The samples were heated from 25 to $145^{\circ} \mathrm{C}$ at a heating rate of $1^{\circ} \mathrm{C} / \mathrm{min}$. The system works according to the international standards (e.g. DIN 51045 or ASTM 831).

\section{Results and discussion}

\subsection{The influence of different coupling agents on the thermal conductivity of composite materials}

Respectively choose untreated $\mathrm{ZnO}$ and the $\mathrm{ZnO}$ processed by OL-AT1618, NDZ 132 and KH550+ MPPW, and put the filler into the mixing mill together with polypropylene for blending, molding and sampling. Then, the thermal conductivity of the materials can be obtained as shown in Figure 2. The thermal conductivity of composite made by filling polypropylene with $\mathrm{ZnO}$ is very low when the content of filler is very low. The difference is not obvious as shown in Table 2. However, the processing is very difficult when the content of filler is too high. Based on the experience of dozens of experiments, a content of $40 \mathrm{vol} \%$ is adopted. As the particle diameter of $\mathrm{ZnO}$ is relatively small, which is only about $200 \mathrm{~nm}$, a higher content

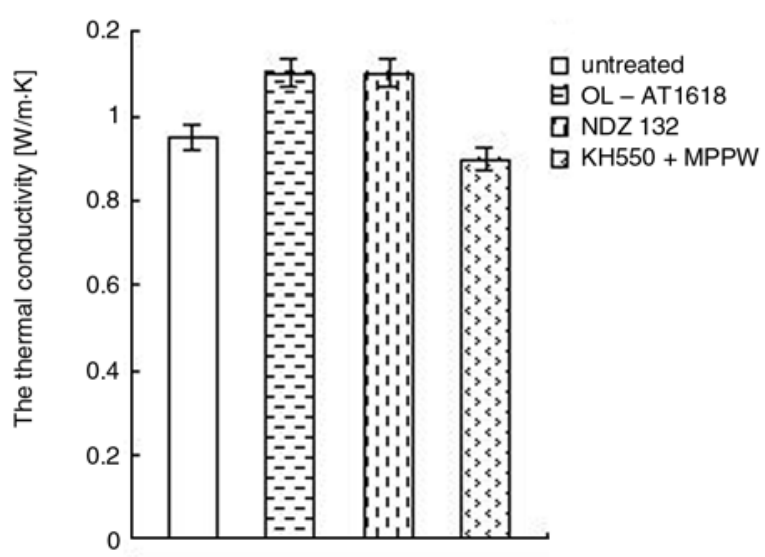

Figure 2. The influence of different filler surface treatment on the thermal conductivity of material
( $2 \mathrm{wt} \%)$ is adopted for filler surface processing agent.

From Figure 2, it can be known that, when the same content is adopted, the composite material, which is blended with a low-molecular coupling agent modified filler, obtains the optimal thermal conductivity that is $1.10 \mathrm{~W} / \mathrm{m} \cdot \mathrm{K}$. The composite material filled with untreated $\mathrm{ZnO}$ obtains a lower thermal conductivity that is about $0.95 \mathrm{~W} / \mathrm{m} \cdot \mathrm{K}$. The composite material produced by filling polypropylene with macro-molecular modified $\mathrm{ZnO}$ obtains the lowest thermal conductivity that is about $0.90 \mathrm{~W} / \mathrm{m} \cdot \mathrm{K}$.

\subsection{The influence of different contents of cou- pling agent on the thermal conductivity of the composite material}

Choose aluminium and titanium complex coupling agent (OL-AT1618), which is relatively effective in improving the thermal conductivity of material after the filler surface treatment, then process $\mathrm{ZnO}$ by different concentrations at $0.5 \%, 1.0 \%, 1.5 \%$, $2.0 \%, 3.0 \%$ and $5.0 \%$. Blend the processed filler $(40 \mathrm{vol} \%)$ and polypropylene $(60 \mathrm{vol} \%)$ in the mixing mill, and mold to make samples. The thermal conductivities of them are shown as Figure 3.

From Figure 3, it is known that the adding of this coupling agent can considerably improve the thermal conductivity of material. Particularly, only $0.5 \%$ will result in an increase on the thermal conductivity by $10 \%$. Then, with the increase of the content of coupling agent, the increase of thermal

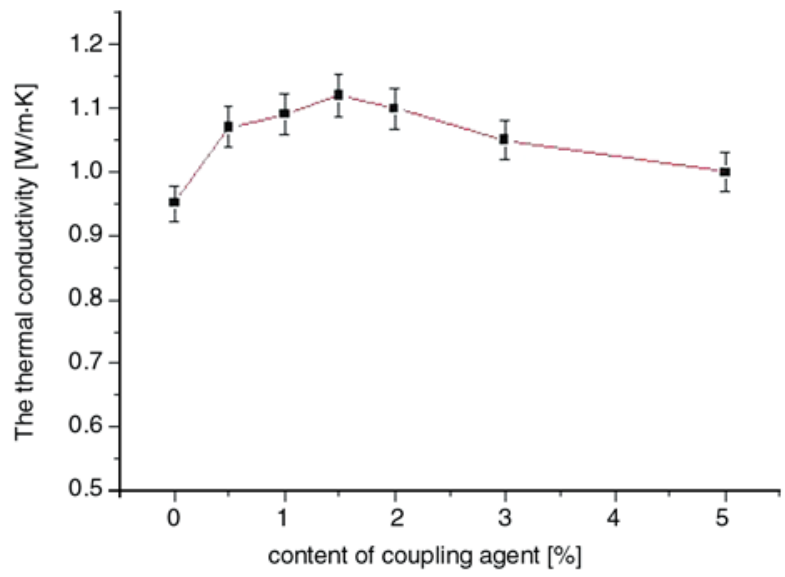

Figure 3. The influence of different content of coupling agent on the thermal conductivity

Table 2. The effect of filler treatment on thermal conductivity of composites in the same filler volume contents (23.4 vol\%)

\begin{tabular}{|c|c|c|c|c|}
\hline Filler $(\mathbf{Z n O})$ & Untreated & OL-AT1618 & NDZ 132 & KH550+MPPW \\
\hline Thermal conductivity $[\mathrm{W} / \mathrm{m} \cdot \mathrm{K}]$ & $0.59 \pm 0.02$ & $0.63 \pm 0.02$ & $0.61 \pm 0.02$ & $0.54 \pm 0.02$ \\
\hline
\end{tabular}


conductivity is slowing down and the thermal conductivity reaches the peak when the content of coupling agent is about $1.5 \%$. After that, the thermal conductivity starts to decrease with the further increase of coupling agent.

For this study, because the adding of low-molecular coupling agent can remarkably improve the adhesion of two-phase interfaces, the concentration of the defects in the composite materials decreases and thus the thermal conductivity of the composite will increase as well by reducing the interfacial phonon scattering between matrix and fillers [13]. Subsequently, with the increase of the content of coupling agent, such kind of improvement keeps going on and the thermal conductivity of composite is increasing slowly. Until the coupling agent finishes the monomolecular layer coverage on filler surface, the composite material obtains the highest thermal conductivity. Thereafter, the further increased coupling agent cannot combine the groups on filler surface. During processing, this part of coupling agent may enter matrix and influence its molecular chain array. Thus, the crystallization of the matrix will change as well so that its thermal conductivity will decrease. As a result, the thermal conductivity of composite will decrease accordingly.

\subsection{The FTIR analysis of the surface graft situation of the filler}

One gram picked sample was wrapped with filter paper. Then it was put into the Soxhlet extractor with 1,2,3,4-tetrahydronaphthalene. Seventy two hours later, the filler powders were taken out and analyzed with FTIR after drying. In Figure 4, from the top down, there are the FR-IR spectra of $\mathrm{ZnO}$ raw material (Spectrum 1), untreated $\mathrm{ZnO}$ after extraction (Spectrum 2), $\mathrm{ZnO}$ processed with OLAT1618 after extraction (Spectrum 3), ZnO processed with NDZ 132 after extraction (Spectrum 4), and infrared spectrum of $\mathrm{ZnO}$ processed with KH550+MPPW after extraction (Spectrum 5). Spectrum 2 is very similar to spectrum 1 , and the PP characteristic bands at 2953 and $2920 \mathrm{~cm}^{-1}$ are weak. It shows that the adhesion between untreated $\mathrm{ZnO}$ and $\mathrm{PP}$ is mainly based on physical interactions, so that the chemical bond in two-phase interface is very weak.

Spectrum 3 exhibits three characteristic bands of $\mathrm{CH}_{3}, \mathrm{CH}_{2}, \mathrm{Ti}-\mathrm{O}$ at $2926,2856,1559 \mathrm{~cm}^{-1}$, respec-

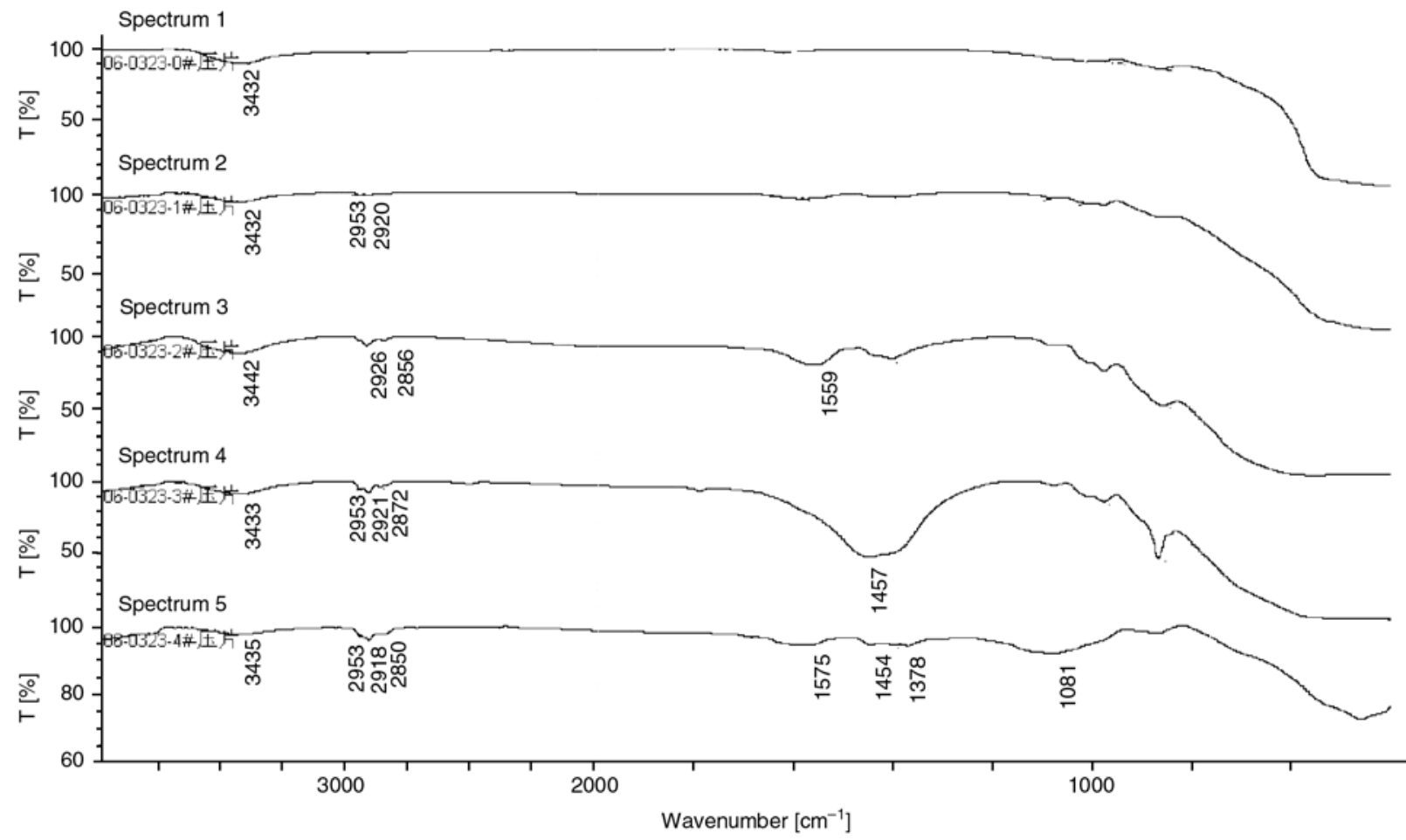

Figure 4. FTIR spectra of extracted fillers. From top down: $\mathrm{ZnO}$ raw material (Spectrum1), untreated $\mathrm{ZnO}$ after extraction (Spectrum 2), ZnO processed with OL-AT1618 after extraction (Spectrum 3), ZnO processed with NDZ 132 after extraction (Spectrum 4), and infrared spectrum of $\mathrm{ZnO}$ processed with KH550+MPPW after extraction (Spectrum 5) 
tively, which means the surface of $\mathrm{ZnO}$ has combined with OL-AT 1618, while the characteristic band of $\mathrm{Al}-\mathrm{O}$ bond does not appear because the content of coupling agent is too small.

In spectrum 4 there appears a broad band at $1457 \mathrm{~cm}^{-1}$, which should be the result of overlapping of NDZ132 characteristic bands, such as Ti-O bond, some PP characteristic bands etc. Meanwhile, the characteristic bands of alkyl appear at 2953, 2921, $2872 \mathrm{~cm}^{-1}$, which means the surface of ZnO has grafted NDZ132.

In spectrum 5 there appears the broad band of $\mathrm{Si}-\mathrm{O}$ at $1081 \mathrm{~cm}^{-1}$. Meanwhile the hydroxyl broad band remarkably weakens at $3435 \mathrm{~cm}^{-1}$, which means lots of hydroxyls on the surface of $\mathrm{ZnO}$ chemically bonded KH550. In addition, the MPPW characteristic bands appear at 2953, 2918, 2850, 1454, $1378 \mathrm{~cm}^{-1}$ and so on, which means KH550 subsequently reacted with MPPW by chemical bonding and thus realized the task of macro-molecular modification.

\subsection{The SEM analysis of filler surface}

Figure 5 shows the SEM micrographs of $\mathrm{ZnO}$ particles. (a) is raw materials. (b), (c), (d) and (e) are respectively the untreated $\mathrm{ZnO}$, the $\mathrm{ZnO}$ processed by OL-AT1618, the ZnO processed by NDZ132, and the $\mathrm{ZnO}$ processed by KH550+MPPW, obtained from the blend of $\mathrm{ZnO} / \mathrm{PP}$ by Soxhlet extraction. As shown by Figure 5, most of the $\mathrm{ZnO}$ particle diameters range from 100 to $400 \mathrm{~nm}$, which are close to the nano-filler level. Thus, they have considerable surface energy and are quite easy to aggregate, which is approved by the micrograph (a). The surface condition of untreated $\mathrm{ZnO}$, which is obtained from the blend by extraction, is nearly the same as $\mathrm{ZnO}$ raw material, and has considerable surface energy as well. Thus, micrograph (a) and micrograph (b) are very similar.

As shown by the FTIR spectrum of samples extracted from the blend, the surface of the $\mathrm{ZnO}$ processed by OL-AT1618, NDZ132 contains relevant graft coupling agents, which considerably modified the surface condition of the filler. So the surface energy decreases and the aggregation among particles decreases as well. During the photographing, it can be found that there is no aggregation of a large quantity of particles. Most of the particles are distributed individually as shown in micrograph (c) and (d). So after treatment of filler like this, composites will show better filler dispersion and wettability than in the case of untreated fillers. It's advantageous to improve the thermal conductivity of composite.

However, the $\mathrm{ZnO}$ processed by $\mathrm{KH} 550+\mathrm{MPPW}$ is covered by macro-molecular coupling agent on the surface, and even after extraction, there are still lots of macro-molecular chains grafted to the surface of filler. As shown in micrograph (e), after the $\mathrm{ZnO}$ is taken out of the extracting device and the solvent is completely dried by volatilization, the particles of $\mathrm{ZnO}$ are bonded together by the effect of big molecular chains.

\subsection{The distribution of filler in matrix and the two-phase interface}

Choose the fracture surface of all samples and the SEM micrographs can be obtained as shown in Figure 6. For untreated $\mathrm{ZnO}$ blended with PP, the compatibility between filler and matrix is not ideal. As shown in figure (a), most $\mathrm{ZnO}$ particles are directly pulled out of matrix, and the surface of particles is quite smooth and not covered by PP matrix. As for the poor compatibility, there are tiny gaps between filler and matrix, which results in the decrease of the thermal conductibility of composite on account of the interfacial phonon scattering.

Regarding the macro-molecular coupling agent processed $\mathrm{ZnO}$, because the surface of filler is covered by a layer of MPPW, it presents the best compatibility with matrix. It can be seen from the SEM micrograph of figure (d), that the $\mathrm{ZnO}$ particles are almost all planted in the PP matrix and there is nearly no filler pulled out of the matrix. As how much the thermal conductive filler can improve the thermal conductivity of composite mainly relies on the thermal conductive network formed by filler in the matrix, when the filler is covered by a layer of polymer matrix, such a layer obviously becomes the thermal resistance layer of the thermal conductive channel, which will definitely reduce the thermal conductivity of composite.

As for $\mathrm{ZnO}$ processed by OL-1618 and NDZ132, when it is blended with PP, the compatibility between filler and matrix has been considerably improved. As shown in the figure (b) and (c), most of the $\mathrm{ZnO}$ particles on the fracture surface are still in the matrix, even the part exposed outside are covered by some PP matrix. Under such a condition, the $\mathrm{ZnO}$ particles can not only form a directly 


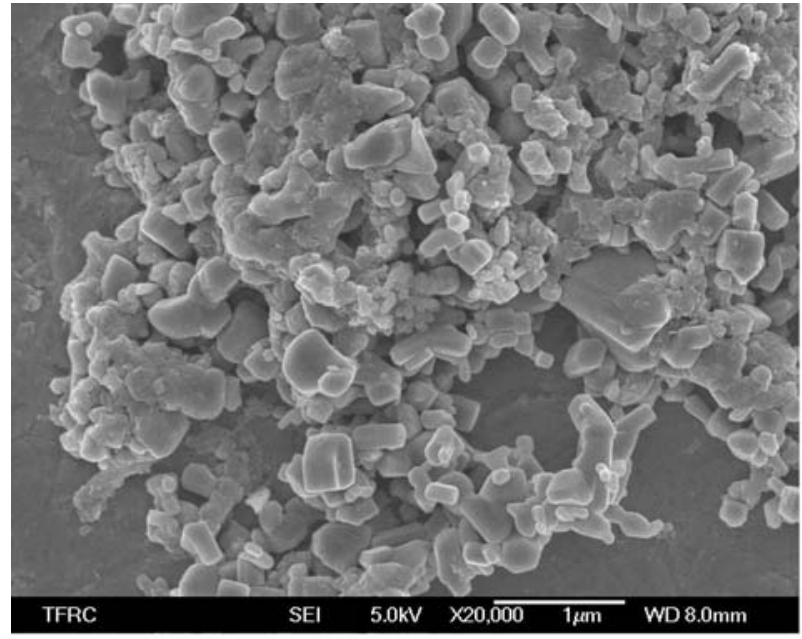

a)

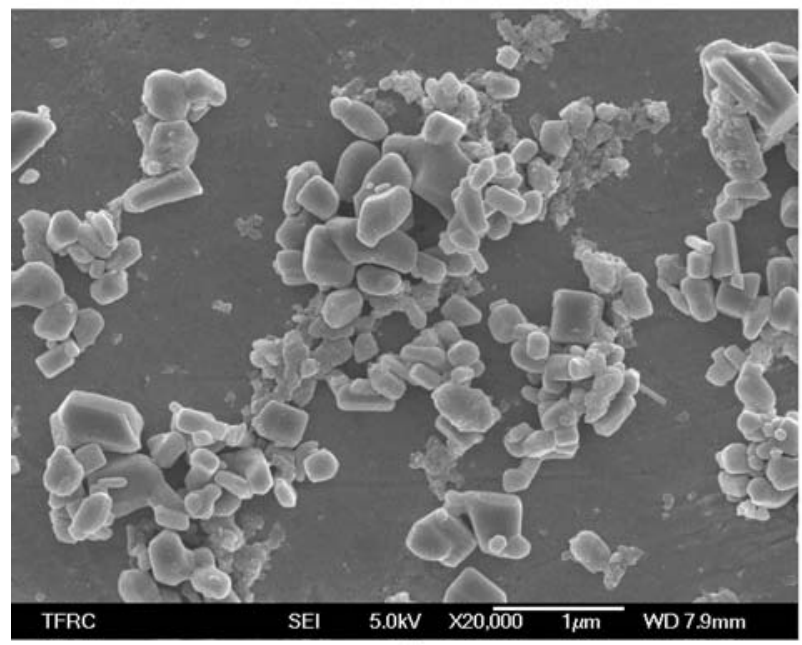

c)

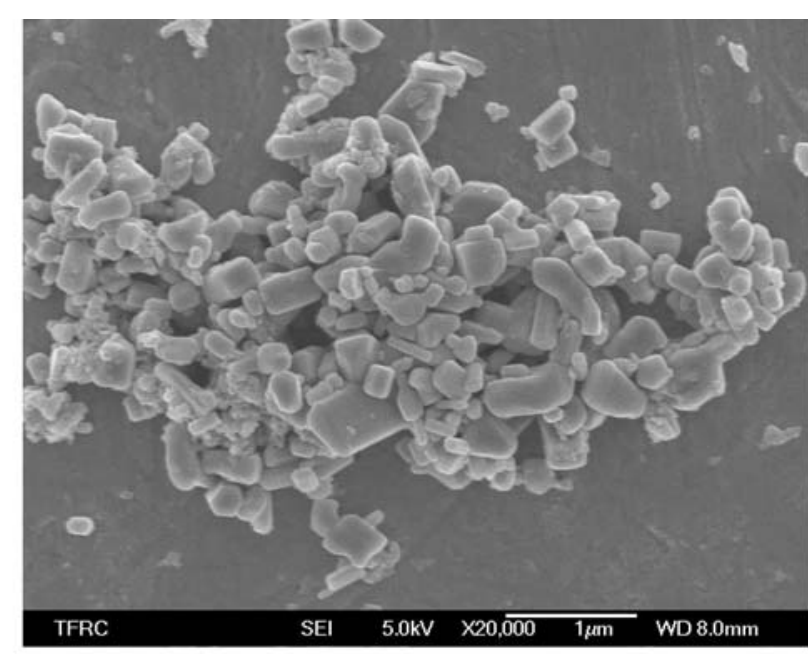

b)

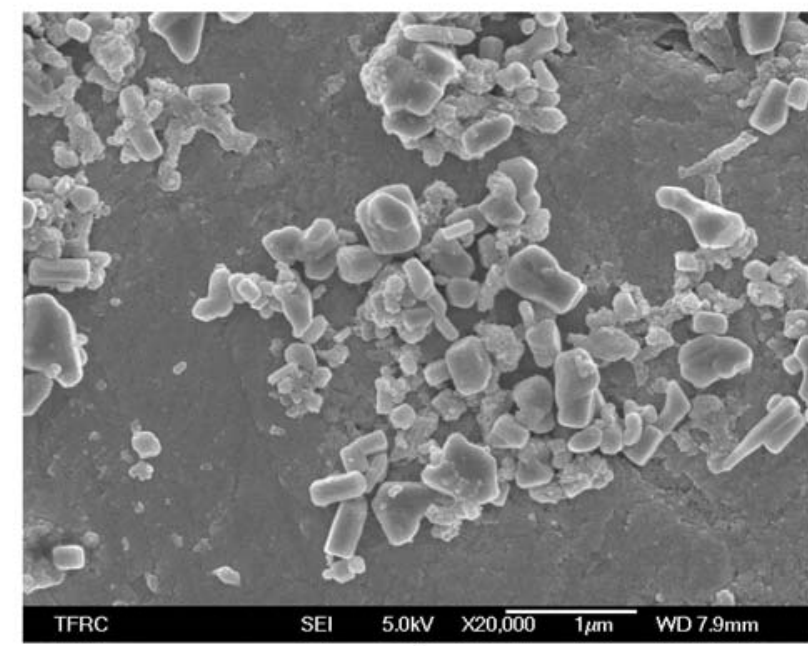

d)

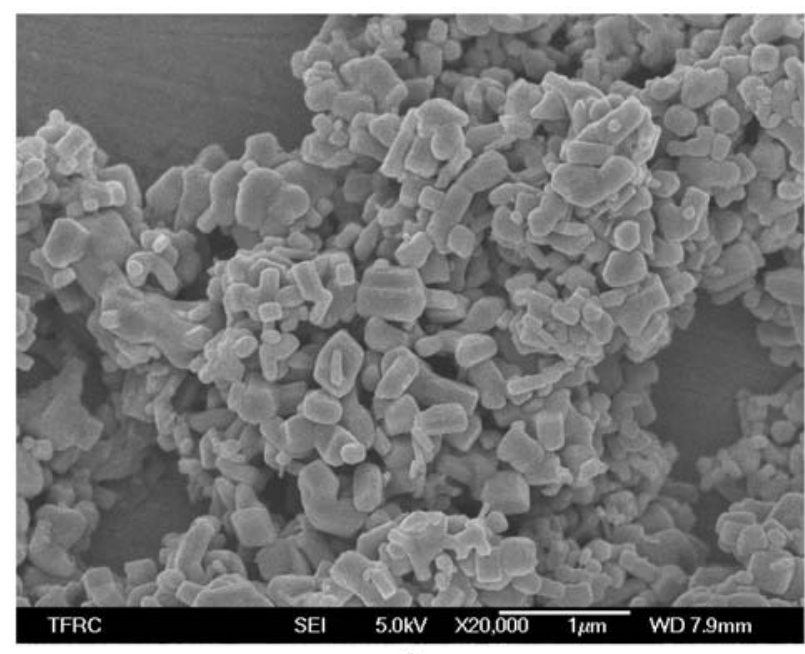

e)

Figure 5. The SEM micrograph of filler. a) material, b) untreated, c) OL-AT 1618, d) NDZ 132, e) KH550+MPPW

interlinked network structure, but also minimized the number of tiny gaps in the interface between filler and matrix. Such a composite material can obtain the optimal thermal transmission effect.

\subsection{The CTE of composites containing filler}

The effect of filler treatment on CTE of composites is listed in Figure 7. As shown, the CTE of composites have been decreased effectively by treating filler. It is due to increasing wettability and disper- 


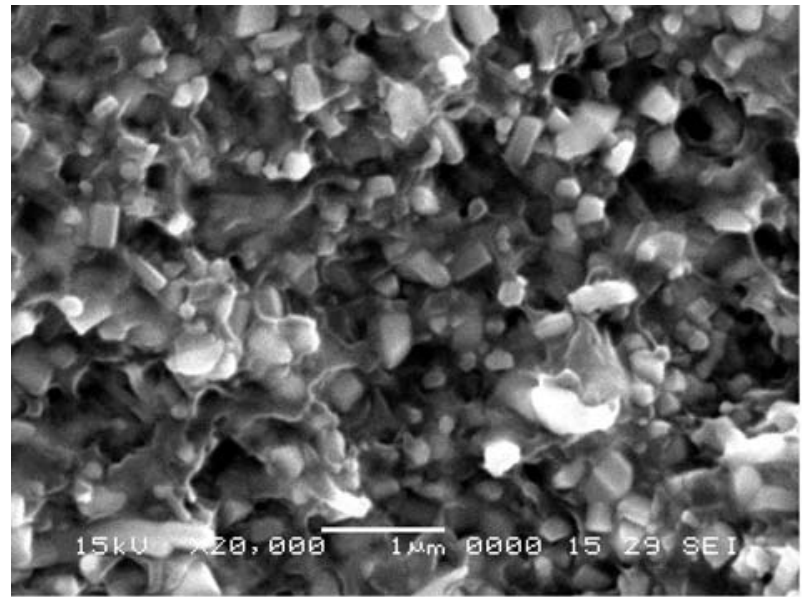

a)

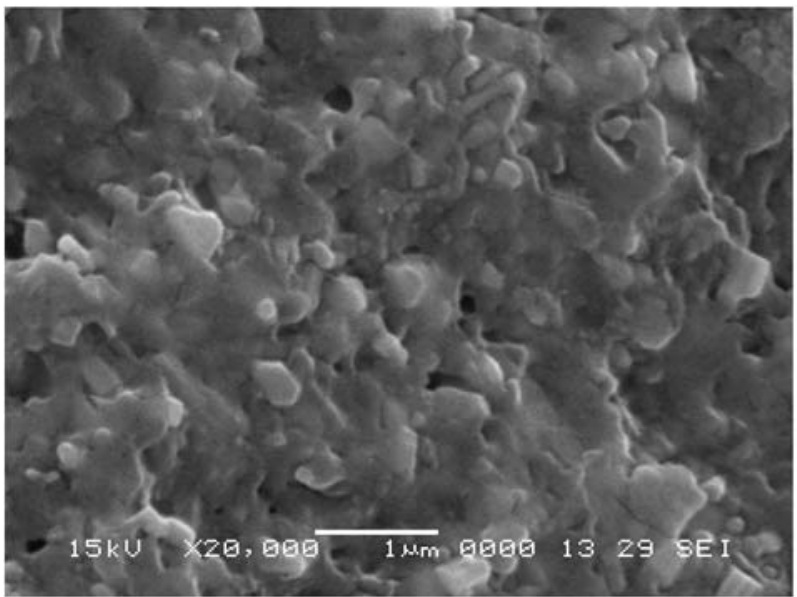

c)

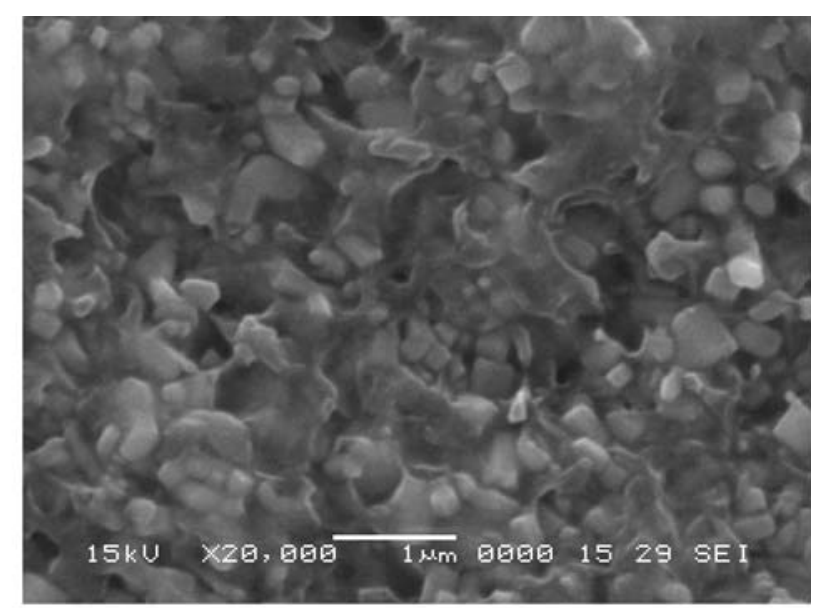

b)

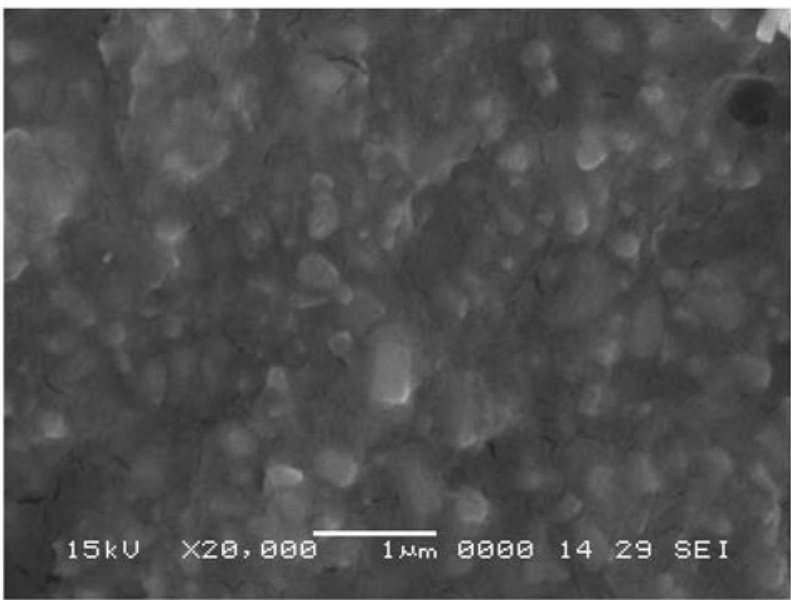

d)

Figure 6. The SEM micrograph of fracture surface. a) untreated, b) OL-AT 1618, c) NDZ 132, d) KH550+MPPW

sion of particle filled composites [14]. There are many tiny gaps between filler and matrix in the untreated $\mathrm{ZnO} / \mathrm{PP}$ blend, which is the main reason

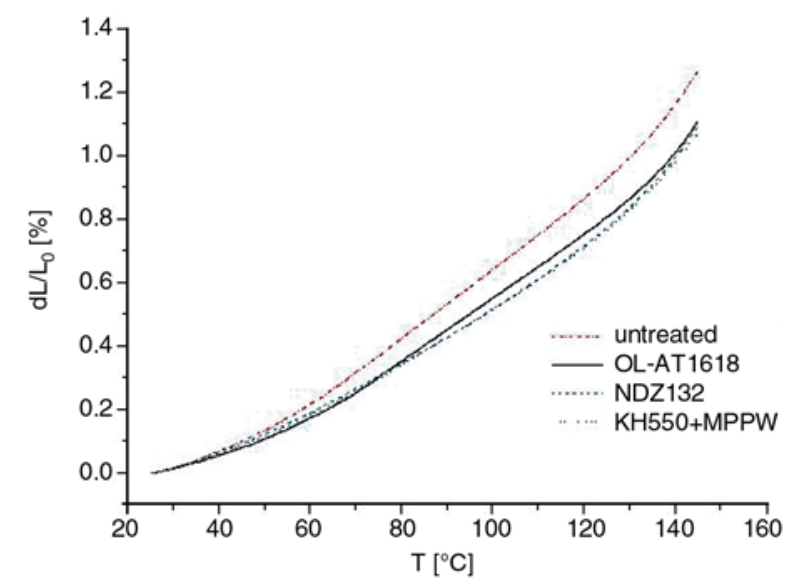

Figure 7. The effect of filler treatment on CTE of composites in the same filler contents (40 vol\%) resulting in the larger CTE than the case of the treated. From Table 3, it can be found that the CTE of composites with treated filler decrease about $15 \%$ from 25 to $145^{\circ} \mathrm{C}$. But the difference between the CTE of composites with filler treated with 3 kinds of coupling agent is approximate. Thus, the better adhesion of two-phase interface, the lower CTE of composites.

\section{Conclusions}

Using low-molecular coupling agents (OLAT1618, NDZ 132) to modify the surface of $\mathrm{ZnO}$ could improve the adhesion of filler and matrix interfaces and reduce the defaults in the two-phase interface so that the thermal conductivity was enhanced by minimizing the interfacial phonon scattering. Unmodified $\mathrm{ZnO}$ /polypropylene blend

Table 3. The CTE of composites with treated filler in the same filler contents ( $40 \mathrm{vol} \%$ ) from 25 to $145^{\circ} \mathrm{C}$

\begin{tabular}{|c|c|c|c|c|}
\hline Filler & Untreated & OL-AT1618 & NDZ132 & KH550+MPPW \\
\hline CTE $10^{-6} / \mathrm{K}^{-1}$ & 105.7 & 92.4 & 91.2 & 89.2 \\
\hline
\end{tabular}


has got many tiny gaps in the two-phase interface and then resulted in the decrease of thermal conductivity; while using the modification method of covering the surface of $\mathrm{ZnO}$ with macro-molecular coupling agent could remarkably improve the adhesion of two-phase interface, but seriously reduced the thermal conductivity of the composite material because of the thermal resistance layer produced by the coverage of polypropylene layer on the surface of filler.

Surface treatment of filler was found to be effective in reducing the $\mathrm{CTE}$ at the same filler content.

In the $\mathrm{ZnO}$ /polypropylene blend system, the thermal conductivity of composite increased first and then decreased with the increasing content of coupling agent. It reached the optimal value when the content of coupling agent was $1.5 \mathrm{wt} \%$ of filler.

\section{References}

[1] Armes S. P., Gottesfeld S., Beery J. G., Garzon F., Agnew S. F.: Conducting polymer-colloidal silica composites. Polymer, 32, 2325-2330 (1991).

[2] Choy C. L., Luk W. H., Chen F. C.: Thermal conductivity of highly oriented polyethylene. Polymer, 19, 155-162 (1978).

[3] Heiser J. A., King J. A.: Thermally conductive carbon filled nylon 6,6. Polymer Composites, 25, 186-193 (2004).

[4] Wang Q., Gao J., Hua Z. K.: The high-density polyethylene composites with high thermal conductivity. CN 1246495A, China (2000).
[5] Liu G., Yi G. W.: Study on the plate heat exchangers of fluoroplastics and graphite and their applications. Chemical Equipment Technology, 19, 26-30 (1998).

[6] Zhu J. R., Zhang X. H., Xu C. X.: Research and applications of thermal conducting polymer. Polymer Materials Science and Engineering, 16, 17-21 (2000).

[7] Yokota H., Yamada S., Ibukiyama M.: Effect of large $\beta-\mathrm{Si}_{3} \mathrm{~N}_{4}$ particles on the thermal conductivity of $\beta$ $\mathrm{Si}_{3} \mathrm{~N}_{4}$ ceramics. Journal of the European Ceramic Society, 23, 1175-1182 (2003).

[8] Zhao J. X.: Silicon carbide fibers and their composite. New Carbon Materials, 11, 15-19 (1996).

[9] Toshiki K.: Polyamide composition for housing of electronic parts. JP 0379 666, Japan (1991).

[10] Akovali G., Dilsiz N.: Studies on the modification of interphase/interfaces by use of plasma in certain polymer composite systems. Polymer Engineering and Science, 36, 1081-1086 (1996).

[11] Qian X., Pu Y. Q., Jin Y. D.: Effect of coupling agents on mechanical properties of heat conductive plastics. Plastics, 21, 20-22 (1992).

[12] Zhao K.: The synthesis and related application about the emulsion of acylate/polyolefin. Post doctor report. East China University of Science and Technology (2004).

[13] Berman R.: Thermal conduction in solids. Clarendon press, Oxford (1976).

[14] Lee G. W., Park M., Kim J., Lee J. I., Yoon H. G.: Enhanced thermal conductivity of polymer composites filled with hybrid filler. Composites, Part A: Applied Science and Manufacturing, 37, 727-734 (2006). 